\title{
Effects of vitamin E supplementation during erythropoietin treatment of the anaemia of prematurity
}

\author{
A Pathak, P Roth, J Piscitelli, L Johnson
}

Arch Dis Child Fetal Neonatal Ed 2003;88:F324-F328

See end of article for authors' affiliations

....................

Correspondence to: Dr P Roth, Director of Neonatology, Staten Island University Hospital - 4E, 475 Seaview Avenue, Staten Island, NY 10305, USA; proth@siuh.edu

Accepted 27 August 2002

\begin{abstract}
Aims: To evaluate the effects of vitamin $\mathrm{E}$ supplementation on haemoglobin concentration and the requirement for transfusion in premature infants treated with erythropoietin and iron.

Methods: Randomised, double blind, placebo controlled trial. Thirty infants $\leqslant 32$ weeks gestation and $\leqslant 1250 \mathrm{~g}$ birth weight, who were defined as stable based on minimal requirements for respiratory support and phlebotomy, and absence of major congenital anomalies were enrolled. All were treated with erythropoietin and iron, and were randomised to receive, in addition, either vitamin E $50 \mathrm{IU} /$ day or placebo for eight weeks or until discharge, whichever came first.

Results: Despite higher vitamin E ( $\alpha$-tocopherol) levels in the experimental group in weeks 3 (49.0 v $28.1 \mathrm{~mol} / \mathrm{l})$ and $8(66.2 \vee 38.5 \mathrm{\mu mol} / \mathrm{l})$, there were no differences in haemoglobin, reticulocyte count, iron concentration, or transfusion requirement.

Conclusions: Oral vitamin E supplementation at $50 \mathrm{lU} /$ day does not increase the response of preterm infants to erythropoietin and iron. Vitamin $\mathrm{E}$ obtained through standard nutrition may have been sufficient or higher doses may be required.
\end{abstract}

$\mathrm{E}$ rythropoietin, the primary growth factor for erythropoiesis in both the fetus and the newborn infant, responds primarily to hypoxic stimuli. While the postnatal increase in oxygenation results in a decrease in its production leading to diminished erythropoiesis and a decline in haemoglobin concentration, ${ }^{1}$ the circulating concentrations of erythropoietin in premature infants seem disproportionately low relative to the degree of anaemia. ${ }^{2-4}$ This normochromic, normocytic anaemia, referred to as anaemia of prematurity, is characterised by an inability to increase erythropoietin production even in the face of symptoms of impaired oxygen delivery. ${ }^{4}$

Although numerous trials have shown that exogenous recombinant human erythropoetin (rhEpo) is capable of stimulating erythropoiesis, both in vitro and in vivo, ${ }^{5-10}$ the impact on transfusion requirements has been variable. ${ }^{569}$ In addition to the implementation of strict transfusion guidelines, investigators have focused on optimising the timing and dosing of rhEpo, ${ }^{7810}$ as well as the need for supplementation with high doses of iron to prevent the appearance of hypochromic red blood cells and decreases in ferritin levels. ${ }^{7}$ However, previous work has shown that in the setting of deficient perinatal red cell antioxidant mechanisms, valent iron can act as a catalyst in the autooxidation of unsaturated fatty acids, which are essential components of red blood cell membranes, and contribute to anaemia by increasing haemolysis. ${ }^{11}$

Haemolysis resulting from therapeutic doses of iron is of particular concern in the setting of deficiency of vitamin E, which acts as cellular oxidant to prevent lipid peroxidation of the red blood cell membrane. Newborn infants have low circulating concentrations of vitamin $\mathrm{E}$ owing to placental impermeability, ${ }^{12}$ transient lipoproten deficiency at birth, ${ }^{13}$ and decreased absorption from the preterm intestine, especially in the presence of iron. ${ }^{14}$ Although conflicting results exist, ${ }^{15}$ previous data have shown that daily supplementation with vitamin E, beginning at 10 days of age in preterm infants, results in significantly higher haemoglobin concentrations at 8-10 weeks. ${ }^{16}$ Whether this effect is owing to the role of vitamin E as an antioxidant or as an erythropoietic factor, as has been shown in animals and humans under select conditions, is unknown. ${ }^{17}$

In this pilot study, we hypothesised that vitamin E supplementation in premature infants treated with rhEpo and iron would result in a reduced requirement for transfusions and in higher haemoglobin concentrations.

\section{MATERIALS AND METHODS \\ Patient population}

Preterm infants were eligible for the study if they were born at $\leqslant 32$ weeks gestational age and weighed $\leqslant 1250 \mathrm{~g}$ at birth at the Weiler Hospital of the Albert Einstein College of Medicine, Jacobi Hospital, or North Central Bronx Hospital. Patients were started on parenteral nutrition as soon after birth as electrolytes were stable. A multivitamin preparation (MVI Pediatric, Astra Pharmaceuticals) containing $1.4 \mathrm{mg}$ $\alpha$-tocopherol acetate $/ \mathrm{ml}$ was added to total parenteral nutrition (TPN) solutions at doses of 1.5 and $3.25 \mathrm{ml} /$ day to infants weighing $<1 \mathrm{~kg}$ and $>1 \mathrm{~kg}$, respectively. Babies were deemed clinically stable based on phlebotomy losses $<7.5$ $\mathrm{ml} /$ week and on the requirement for minimal respiratory support defined as follows: (1) $\mathrm{FiO}_{2} \leqslant 0.35$; (2) intermittent mechanical ventilation $\leqslant 25$ breaths/minute; and (3) mean airway pressure $\leqslant 8 \mathrm{~cm}$. Babies were excluded if they: (1) had disease(s) involving any major organ system; (2) had life threatening congenital malformations or sepsis; (3) had isoimmunisation with clinically apparent haemolytic anaemia; (4) had other haemolytic disorders; (5) had grade III or greater intraventricular haemorrhage; or (6) were clinically unstable by the criteria noted above. Written informed consent was obtained from parents of all infants prior to enrolment of patients in the study. The study was approved by the Institutional Review Board of the Albert Einstein College of Medicine.

\section{Study design}

Subjects were enrolled in this randomised, double blind, placebo controlled study through the selection from separate packs of sealed envelopes, divided evenly between the placebo and experimental groups in the pharmacy at each site by a pharmacist not involved in the clinical care of the patients. The investigators felt that a trial of 30 patients would be sufficient for a pilot project to assess safety and possible efficacy. There was no formal sample size calculation. All patients, once 


\begin{tabular}{|c|c|c|}
\hline & Experimental $(n=15)$ & Placebo $(n=15)$ \\
\hline Gestational age (wk) & $27.9(0.5)$ & $27.9(0.4)$ \\
\hline Birth weight (g) & $928(44)$ & $899(41)$ \\
\hline $\begin{array}{l}\text { Ventilatory support } \\
\text { (days) }\end{array}$ & $14.3(3.8)$ & $19.9(3.8)$ \\
\hline \multicolumn{3}{|l|}{$\begin{array}{l}\text { Age (days) at } \\
\text { initiation of: }\end{array}$} \\
\hline Erythropoietin & $14.6(1.9)$ & $14.3(2.3)$ \\
\hline Feeds & $12.3(2.5)$ & $10.3(1.7)$ \\
\hline Full feeds & $29.7(3.7)$ & $36.1(5.4)$ \\
\hline $\mathrm{Fe}$ & $22.7(2.8)$ & $24.7(2.9)$ \\
\hline $\begin{array}{l}\text { Study enrolment } \\
\text { (days) }\end{array}$ & $24.4(4.0)$ & $28.1(2.6)$ \\
\hline $\begin{array}{l}\text { Day } 1 \text { haemoglobin } \\
\text { (g/l) }\end{array}$ & $145.0(7.4)$ & $145.0(4.5)$ \\
\hline $\begin{array}{l}\text { Day } 1 \text { reticulocyte } \\
\text { count }\left(\times 10^{\circ} / 1\right)\end{array}$ & $181.2(15.8)$ & $234.1(28.7)$ \\
\hline Phlebotomy losses (ml) & $19.9(2.0)$ & $21.2(1.6)$ \\
\hline Discharge weight (g) & $2098(71)$ & $2082(78)$ \\
\hline Length of stay (days) & $69.7(6.2)$ & $69.0(6.0)$ \\
\hline
\end{tabular}

Data expressed as mean (SEM).

determined to be clinically stable as outlined in the previous section, were treated with erythropoietin subcutaneously, beginning with a dose of 100 units/kg/day given Monday to Friday for a total of eight weeks or until discharge, whichever came first. If after one week of treatment, the absolute reticulocyte count remained $<200 \times 10^{9} / \mathrm{l}$, the dose was increased to $200 \mathrm{units} / \mathrm{kg} /$ day. Once enteral feedings equalled or exceeded $40 \mathrm{ml} / \mathrm{kg} /$ day, supplementation with oral iron (Ferinsol) at a dose of $6 \mathrm{mg} / \mathrm{kg} /$ day and $1.0 \mathrm{ml}$ of a multivitamin preparation containing 5 units/ml of vitamin $\mathrm{E}$ was initiated.

\section{Vitamin E supplementation}

In addition to achieving stability and being treated with erythropoietin as outlined above, administration of vitamin $\mathrm{E}$ or placebo was initiated only if enteral feeds had begun $\geqslant 48$ hours prior to enrolment with a minimal total daily energy intake from both intravenous nutrition and enteral feeds of 60 kcal $(0.25 \mathrm{MJ})$ per $\mathrm{kg}$ per day, of which at least $50 \%$ was derived from the latter. Beginning on the first study day, patients in the experimental group received vitamin E 50 IU/day enterally, while subjects in the placebo group received an identical volume of vehicle. Parents, investigators, and clinical staff were all masked to the treatment status of the infants during the study.

\section{Laboratory and clinical monitoring}

Clinical data were recorded prospectively and included gestational age, birth weight, gender, age and weight at study entry, daily weights, energy intake, phlebotomy losses, and volume and number of erythrocyte transfusions both prior and subsequent to study enrolment.

Haemoglobin, haematocrit, and differential white blood cell count were measured in the clinical laboratory at baseline and then weekly as was the routine for babies treated with erythropoietin. During weeks 2-8 of the study, vitamin E levels were measured by high pressure liquid chromotography ${ }^{18}$ and serum iron by spectrophotometry using the FeroZine reagent (Boehringer Mannheim, Indianapolis, IN). ${ }^{19}$

\section{Erythrocyte transfusions}

The decision to administer erythrocyte transfusions was made exclusively by the clinical staff based on criteria described previously. ${ }^{6}$ Briefly, infants were transfused for haematocrits $<0.35$ : (a) if they required $\geqslant 35 \% \mathrm{O}_{2}$ by headbox or $100 \%$ at $>1 / 4$ l/min via nasal cannula; or (b) if they required continuous positive airway pressure (CPAP) or mechanical ventilation at a mean airway pressure of $\geqslant 6 \mathrm{~cm} \mathrm{H}_{2} \mathrm{O}$. Transfusions were
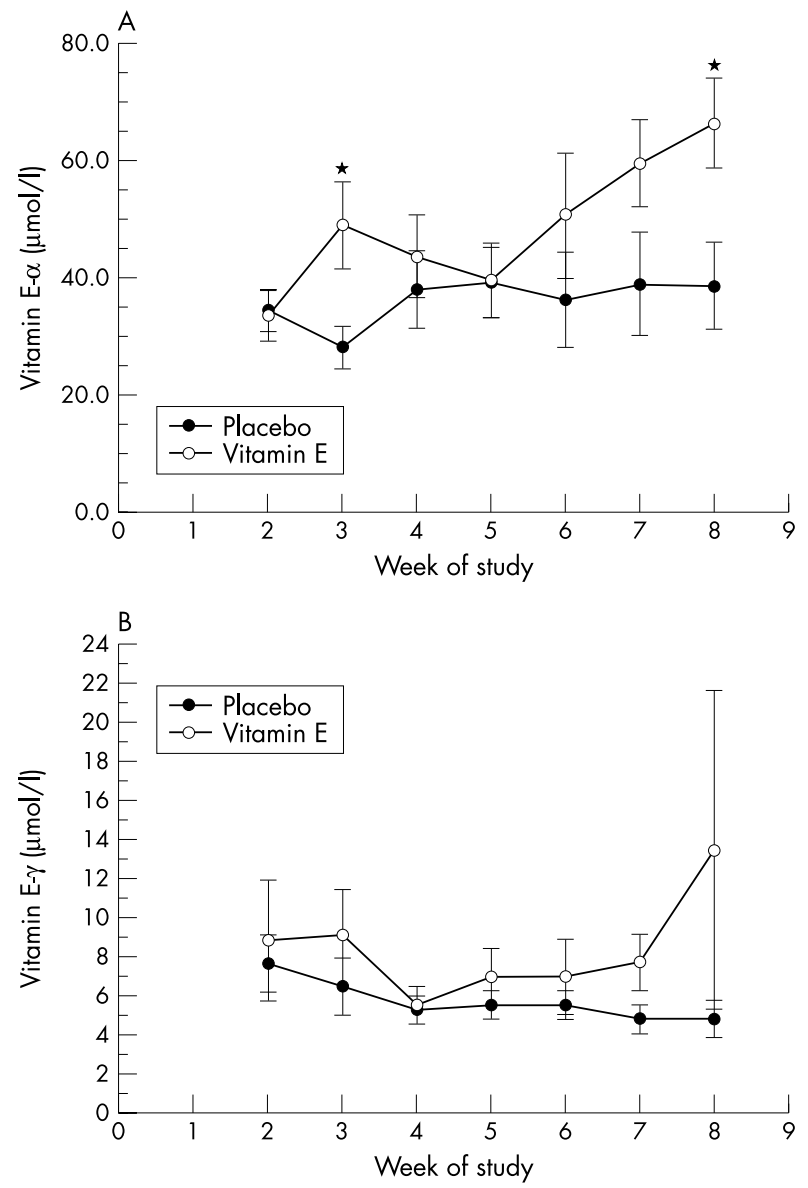

Figure 1 Effects of vitamin $E$ on serum vitamin $E$ levels. Serum levels of $\alpha$-tocopherol (A) and $\gamma$-tocopherol (B) were measured over time (weeks) and expressed as mean (SEM). ${ }^{*} p<0.05$ versus placebo.

administered for haematocrits $\leqslant 0.30$ if subjects: (a) required $<35 \% \mathrm{O}_{2}$ by headbox or $100 \%$ at $<1 / 4 \mathrm{l} / \mathrm{min}$ via nasal cannula; (b) required CPAP or mechanical ventilation at a mean airway pressure of $<6 \mathrm{~cm} \mathrm{H}_{2} \mathrm{O}$; (c) had significant episodes of apnoea and bradycardia (that is, $>9$ episodes/ 12 hours or $\geqslant 2$ episodes requiring positive pressure ventilation/24 hours) while receiving therapeutic doses of methylxanthines; (d) had heart rate $>180$ beats/minute or respiratory rate $>80$ breaths/minute for at least 24 hours; (e) had weight gain $<10 \mathrm{~g} /$ day for at least four days despite the administration of $>100 \mathrm{kcal}(0.4$ $\mathrm{MJ} / \mathrm{kg} / \mathrm{day}$; or (f) were undergoing surgery. Transfusions were administered at haematocrits $\leqslant 0.20$ if patients were asymptomatic but had reticulocytes $<100 \times 10^{9} / 1$. Transfusions were not administered to replace blood removed for laboratory tests alone or for low haematocrit alone.

\section{Statistical analysis}

Data are expressed as mean (SE). Control and study patients were compared using Student's $t$ test; p values less than 0.05 were considered significant.

\section{RESULTS}

Patients in the experimental and placebo groups were comparable in their clinical characteristics including birth weight, gestational age, and postnatal age at the time of initiation of enteral feeds, erythropoietin, and study enrolment (table 1). Phlebotomy losses in the two groups did not differ. There were no differences in the occurrence of complications in the two groups with five cases of sepsis in each (experimental: three coagulase negative staphylococcus, two 

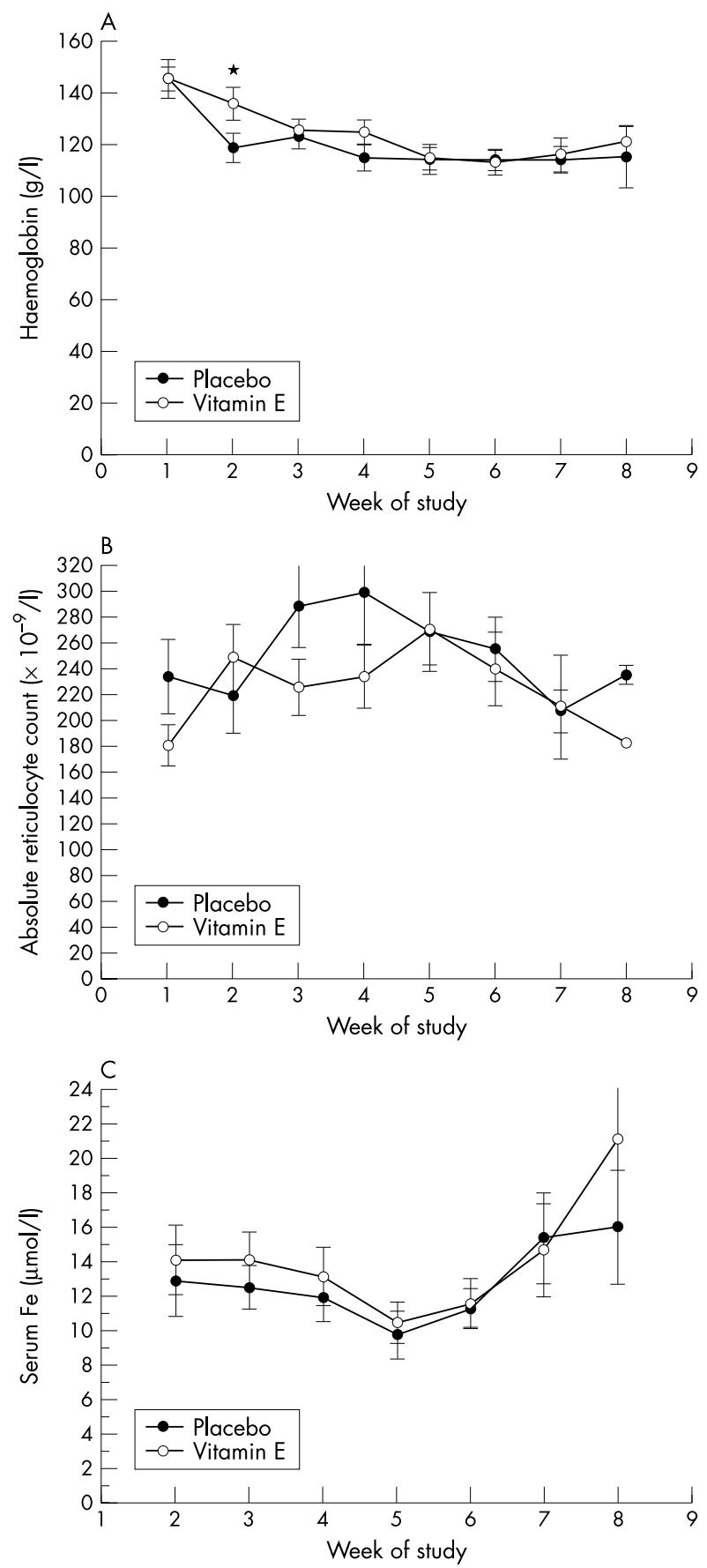

Figure 2 Effects of vitamin $E$ on haematological measurements. Haemoglobin concentrations (A), reticulocyte counts (B), and serum iron concentrations (C) were measured over time (weeks) and expressed as mean (SEM). ${ }^{*} p<0.05$ versus placebo.

Candida; placebo: four coagulase negative staphylococcus, one Klebsiella), one case of necrotising enterocolitis in the experimental group, and one case of patent ductus arteriosus requiring therapy in each group. There was no evidence of significant cholestasis or malabsorption in either group (data not shown). All infants in both groups survived.

Serial measurements of serum vitamin E levels revealed significantly higher levels in the experimental group of the $\alpha$ fraction (fig lA) at study weeks $3(p<0.05)$ and $8(p=0.05)$ and nearly significantly higher levels of the $\gamma$-fraction at week 7 ( $\mathrm{p}=0.058$; fig $\mathrm{lB})$. Cumulative vitamin $\mathrm{E}$ intakes were (mean (SEM)) 476 (33) and 2417 (190) IU for the placebo and experimental groups, respectively, with no apparent correla-
Table 2 Effects of vitamin E on transfusion requirements

\begin{tabular}{lll}
\hline & Experimental & Placebo \\
\hline $\begin{array}{l}\text { Transfusions (no.) } \\
\text { Before }\end{array}$ & $3.0(1.1)$ & $4.1(0.9)$ \\
$\quad$ During & $0.9(0.3)$ & $1.1(0.4)$ \\
$\begin{array}{l}\text { Volume transfused (ml) } \\
\text { Before }\end{array}$ & $35.3(10.6)$ & $46.0(10.0)$ \\
$\quad$ During & $15.5(5.5)$ & $17.8(6.1)$ \\
\hline Data expressed as mean (SEM).
\end{tabular}

tion with circulating levels (data not shown). Examination of haematological parameters revealed a slow decline in haemoglobin (fig 2A) from baseline in both groups, with similar concentrations in both groups other than at week 2, when concentrations in the experimental group were higher (135 V $118 \mathrm{~g} / \mathrm{l} ; \mathrm{p}<0.05)$. Concurrent reticulocyte counts revealed evidence of significant red blood cell production, with absolute counts greater than $180 \times 10^{9} / 1$ and $200 \times 10^{\circ} / 1$ in the experimental and placebo groups, respectively, throughout the study period (fig 2B) with no significant differences between groups. Since prior studies have shown depletion of iron stores during treatment with erythropoietin, ${ }^{20}$ we examined serum iron levels in the two groups. As fig $2 \mathrm{C}$ shows, there is an apparent drop in serum iron levels followed by an increase after week 5 of the study. Again, there were no differences between the two groups. Furthermore, comparison of the two groups showed no significant differences between the white blood cell and platelet counts, both of which were in the normal range (data not shown).

Comparison of the requirement for red blood cell transfusions showed similar needs in both groups both during the approximately 3-4 weeks prior to study enrolment ("Before") and during the eight week study period ("During") (table 2). Results were essentially identical regardless of whether the total number of transfusions (prestudy: vitamin E 3.00 (1.1), placebo 4.1 (0.9), NS; during study: vitamin E 0.9 (0.3), placebo 1.1 (0.4), NS) or the volume $(\mathrm{ml})$ transfused (prestudy: vitamin E 35.3 (10.6), placebo 46.0 (10.0), NS; during study: vitamin E 15.5 (5.5), placebo 17.8 (6.1), NS) were measured (table 2).

\section{DISCUSSION}

As treatment with erythropoietin can result in the rapid depletion of iron stores associated with the production of hypochromic, microcytic red blood cells, ${ }^{7}$ administration of high doses of iron is required, despite the potential production of free radicals leading to oxidant membrane damage with haemolysis. Since the occurrence of this latter effect is potentiated in the setting of vitamin E deficiency relative to the concentrations of polyunsaturated fatty acids, ${ }^{21}{ }^{22}$ we investigated the effects of vitamin E supplementation on erythropoiesis in infants treated with erythropoietin and iron. Vitamin $\mathrm{E}$ occurs as four major tocopherols, $\alpha, \beta, \gamma$, and $\delta$, with the $\alpha$ form being the most abundant and biologically active. Mean plasma tocopherol, the principal form of vitamin E, at birth is $0.2-0.3$ $\mathrm{mg} / \mathrm{dl}(4.6-7.0 \mu \mathrm{mol} / \mathrm{l})$ and increases to $\geqslant 0.5 \mathrm{mg} / \mathrm{dl}$ ( 11.6 $\mu \mathrm{mol} / \mathrm{l})$ by the end of the first week in infants well enough to be fed vitamin E containing milk. ${ }^{23}$ As $\alpha$-tocopherol is the critical antioxidant form of vitamin $\mathrm{E}$, sufficiency may be defined as total tocopherol levels of $\geqslant 0.8 \mathrm{mg} / \mathrm{dl}(18.6 \mu \mathrm{mol} / \mathrm{l})$, which will ensure levels of the $\alpha$ fraction that exceed $0.5 \mathrm{mg} / \mathrm{dl}$ $(11.6 \mu \mathrm{mol} / \mathrm{l}) .^{24}$ The susceptibility to oxidant injury is heightened in the neonatal red blood cell membrane because of the presence of high concentrations of oxidisable unsaturated relative to saturated fatty acids. ${ }^{25}$ Furthermore, a very large percentage of fetuses and by extension, infants born 
prematurely at the time of birth, have levels of red blood cell membrane associated $\alpha$-tocopherol that are below the threshold required to protect against oxidant mediated haemolysis. ${ }^{26}$ Since analysis of red blood cell fatty acid composition was beyond the scope of the above study as well as our own, it is entirely possible that the established requirements for vitamin $\mathrm{E}$ as well as the frequency of its deficiency represent underestimates.

In the present study, administration of supplemental enteral vitamin $\mathrm{E}$ to infants treated with erythropoietin and iron did not result in any significant differences in haemoglobin, reticulocyte count, or the requirement for transfusions. The Committee on Nutrition of the American Academy of Pediatrics recommends that the diet of premature infants should contain at least 1 IU vitamin E/g of linoleic acid, which is approximately equal to $0.6 \mathrm{mg} \mathrm{d}$ - $\alpha$-tocopherol $/ \mathrm{g}$ of polyunsaturated fatty acids. A premature infant on full enteral feeds and multivitamin supplements, which provide a daily intake of $5 \mathrm{IU}$ of vitamin E, receives approximately 5-10 IU/kg/day of this vitamin, while those on parenteral nutrition receive somewhat less. ${ }^{27}$ At the time of study enrolment, study patients had already been receiving vitamin E through the administration of approximately two weeks of exclusive TPN and an additional two weeks of combined parenteral nutrition and enteral feeds. Supplementation with 50 units/day of vitamin $\mathrm{E}$ in the experimental group exceeded the doses of 15-25 units used in previous erythropoietin trials ${ }^{28-31}$ in which vitamin E supplements above those in feeds and multivitamins were administered as part of routine care to all patients. Serial measurements revealed an apparent increase over time in the experimental group in $\alpha$-tocopherol levels, which were significantly greater than the placebo group in the third and eighth weeks of the study. However, during the entire study, mean values for $\alpha$-tocopherol levels in the placebo group exceeded minimal levels for vitamin E sufficiency. Prior supplementation through parenteral nutrition and feedings, therefore, may have blunted potential differences between the two groups. Alternatively, threshold levels for achieving beneficial effects on the haematological parameters measured may have been reached too late in the study. An additional limitation of this study is the measurement of serum rather than red blood cell associated $\alpha$-tocopherol levels, which may correlate better with in vivo antioxidant protection. ${ }^{32}$ However, previous investigators have shown a very strong correlation between levels measured at these two sites. ${ }^{33}$ Although our results may suggest that higher doses of vitamin $\mathrm{E}$ are required, caution is necessary in light of previous experience, where prolonged elevations in serum vitamin $\mathrm{E}$ levels were associated with an increased incidence of sepsis and necrotising enterocolitis in very low birth weight infants. ${ }^{34}$ It is also possible, given the relatively small size of the patient population in this study, that subtle outcome differences may be detectable in future trials with substantially larger enrolments.

Consistent with previous studies, ${ }^{35}$ subjects in the current report received the bulk of transfusions relatively early in their course when maximal phlebotomy losses occurred. Recently proposed protocols have called for the initiation of intravenous erythropoietin and iron dextran soon after birth, ${ }^{35}$ when patients may still be treated with high concentrations of oxygen and/or mechanical ventilation, resulting in a high potential for oxidant mediated red blood cell destruction. This time period, when patients have not yet accumulated adequate stores of tocopherol from parenteral nutrition and feedings, would be an optimal time for further trials of vitamin E supplementation.

\section{ACKNOWLEDGEMENTS}

The authors wish to thank Mr Ron Chan, R Pharm, for his assistance in preparation of the study medications and randomisation of the study subjects.

\section{Authors' affiliations}

A Pathak, P Roth, Department of Pediatrics, Albert Einstein College of

Medicine, Bronx, New York, USA

J Piscitelli, Department of Pathology, Albert Einstein College of Medicine

L Johnson, Department of Pediatrics, University of Pennsylvania,

Philadelphia, PA, USA

Research supported in part by Newborn Pediatrics Fund, Pennsylvania Hospital

\section{REFERENCES}

1 King PJ, Schmidt RL, Roberts RA, et al. Serum erythropoietin levels during infancy: associations with erythropoiesis. J Pediatr 1996;128:791-6.

2 Brown MS, Garcia JF, Phibbs RH, et al. Decreased response of plasma immunoreactive erytropoietin to "available oxygen" in anemia of prematurity. J Pediatr 1984; 105:793-8.

3 Stockman JA, Garcia JF, Oski FA. The anemia of prematurity: factors governing the erythropoietin response. N Engl J Med 1977;296:64750.

4 Stockman JA, Graeber JE, Clark DA, et al. Anemia of prematurity: determinants of the erythropoietin response. J Pediatr 1984;105:78692.

5 Maier RF, Obladen M, Scigalla P, et al. The effect of epoetin beta (recombinant human erythropoietin) on the need for transfusion in very low birth weight infants. N Engl J Med !994;330: 1 173-8.

6 Shannon KM, Keith JF, Mentzer WC, et al. Recombinant human erythropoietin stimulates erythropoiesis and reduces erythrocyte transfusions in very low birth weight preterm infants. Pediatrics 1995;95: 1-8.

7 Kumar P, Shankaran S, Krishnan RG. Recombinant human erythropoietin therapy for treatment of anemia of prematurity in very low birth weight infants: a randomized, double-blind, placebo-controlled trial. J Perinatol 1998;18:173-7.

8 Maier RF, Obladen M, Kattner E, et al. High-versus low-dose erythropoietin in extremely low birth weight infants. J Pediatr 1998; 132:866-70.

9 Ohls RK, Ehrenkranz RA, Lemons JA, et al. A multi-centered, randomized, double-blind, placebo-controlled trial of erythropoietin administration to premature infants $\leqslant 1250$ grams birth weight. Pediatr Res 1999;45:216A

10 Donato H, Vain N, Rendo P, et al. Effect of early versus late administration of human recombinant erythropoietin on trnasfusion requirements inpremature infants: results of a randomized, placebo-controlled, multicenter trial. Pediatrics 2000; 105:1066-72.

11 William ML. Role of dietary iron and fat on vitamin E deficiency anemia of infancy. N Engl J Med 1975;292:877-90.

12 Wright SW, Filer L, Mason KE. Vitamin E blood levels in premature and full term infants. Pediatrics 1951;7:386-93

13 Desai ID, Martinez FE, Dos Santos JE, et al. Transient lipoprotein deficiency at birth: a cause of low levels of vitamin $E$ in the newborn. Acta Vitaminologica Enzymologica 1984;6:71-86.

14 Melhorn DK, Gross S. Vitamin E dependent anemia in the premature infant. Effect of large doses of medicinal iron. J Pediatr 1971;79:569-80

15 Zipursky A, Brown EJ, Watts J, et al. Oral vitamin E supplementation fo the prevention of anemia in premature infants. Pediatrics 1987;79:61-8.

16 Jansson L, Holmberg L, Nilsson B, et al. Vitamin E requirements of preterm infants. Acta Paediatr Scand 1978;67:459-63.

17 Geissler RG. In vitro improvement of bone marrow derived hematopoietic colony formation in HIV positive patients by alpha D tocopherol and erythropoietin. Eur J Haematol 1994;53:101-6.

18 Catiganai GL, Bieri JG. Simultaneous determination of alpha-tocopherol and retinol in plasma or red cells by HPLC. Am J Clin Nutr 1979;32:2143-9.

19 Carter $\mathbf{P}$. Spectrophotometric determination of serum iron at the submicrogram level with a new reagent (ferrozine). Anal Biochem 1971:40:450-8.

20 Messer J, Haddad J, Donato L, et al. Early treatment of premature infants with recombinant human erythropoietin. Pediatrics 1993;92:519-23.

21 Mellhorn D, Gross S. Vitamin E dependent anemia in the pre-term infant. I. Effects of large doses of medicinal iron. J Pediatr 1971;79:569-80.

22 Williams ML, Shott RJ, O'Neal PL, et al. Role of dietary iron and fat on Vitamin E deficiency of infancy. N Engl J Med 1975;292:887-90.

23 Farrell PM. Vitamin E deficiency in premature infants. J Pediatr 1979;95:869-72.

24 Gutcher GR, Lax AM, Farrell PM. Tocopherol isomers in intravenous lipid emulsions and resultant plasma concentrations. J Parent Enteral Nutr 1984;8:269-73.

25 Jain SK. The neonatal erythrocyte and its oxidative susceptibility. Semin Hematol 1989:26:286-300.

26 Cachia O, Leger $\mathrm{CL}$, Buolot $\mathrm{P}$, et al. The red blood cell vitamin $\mathrm{E}$ concentrations in fetuses are related to but lower than those in mothers during gestation: a possible association with maternal Lp(a) plasma levels. Am J Obstet Gynecol 1995;173:42-51.

27 Committee on Nutrition, American Academy of Pediatrics. Nutritional needs of low-birth-weight infants. Pediatrics 1977;60:519. 
28 Brown MS Shapiro $\mathrm{H}$. Effect of protein intake on erythropoietic treatment of anemia of prematurity. J Pediatr 1996;1 28:512-17.

29 Meyer MP, Haworth C, Meyer JH, et al. A comparison of oral and intravenous iron supplementation in preterm infants receiving recombinant erythropoietin. J Pediatr 1996;129:258-63.

30 Ohls RK, Harcum J, Schibler KR, et al. The effect of erythropoietin on the transfusion requirements of preterm infants $\leqslant 750$ grams: a randomized double-blind, placebo-controlled study. J Pediatr 1997;131:661-5.

31 Brown MS, Keith JF III. Comparison between two and five doses a week of recombinant human erythropoietin for anemia of prematurity: a randomized trial. Pediatrics 1999;104:210-15.
32 Mino $M$ Nakagawa $S$ Tamai $H_{\text {, et al }}$ Clinical evaluation of red blood cell tocopherol. Ann N'Y Acad Sci 1982;393:175-8.

33 Jain SK, Wise R, Bocchini JJ. Vitamin E and vitamin E-quinone levels in red blood cells and plasma of newborn infants and their mothers. J Am Coll Nutr 1996;15:44-8.

34 Johnson L, Bowen FW, Abbasi S, et al. Relationship of prolonged pharmacologic serum levels of vitamin $E$ to incidence of sepsis and necrotizing enterocolitis in infants with birth weight 1,500 grams or less. Pediatrics 1985;75:619-38.

35 Ohls RK. The use of erythropoietin in neonates. Clin Perinatol 2000;27:681-96.

\section{Reference linking to full text of more than 200 journals}

\section{Toll free links}

You can access the FULL TEXT of articles cited in Archives of Disease in Childhood online if the citation is to one of the more than 200 journals hosted by HighWire (http://highwire.stanford.edu) without a subscription to that journal.

There are also direct links from references to the Medline abstract for other titles.

www.archdischild.com 